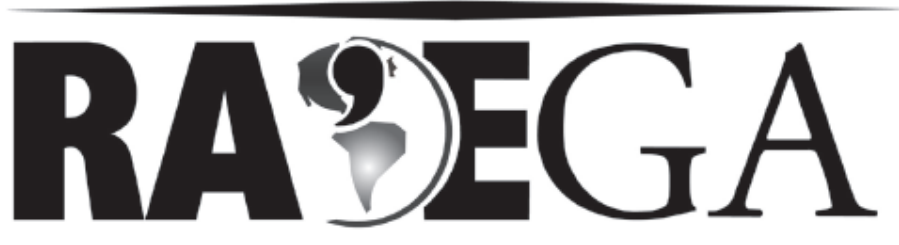

O ESPAÇO GEOGRÁFICO EM ANÁLISE

\title{
PARÂMETROS DE COR E TURBIDEZ COMO INDICADORES DE IMPACTOS RESULTANTES DO USO DO SOLO, NA BACIA HIDROGRÁFICA DO RIO TAQUARAL, SÃO MATEUS DO SUL-PR
}

\author{
COLOR AND TURBIDITY PARAMETERS AS \\ INDICATORS OF IMPACTS RESULTING FROM LAND \\ USE, IN THE WATERSHED OF TAQUARAL RIVER, SAO \\ MATEUS DO SUL - PR
}

\author{
Ângela Marli Ewerling Luíz ${ }^{1}$ \\ Maria Ligia Cassol Pinto ${ }^{2}$ \\ Elizabeth Weinhardt de Oliveira Scheffer ${ }^{3}$
}

\section{RESUMO}

$\mathrm{O}$ abastecimento humano exige água com qualidade. Nesse sentido, 0 presente artigo teve por objetivo relacionar aspectos físicos e de uso do solo com os parâmetros aquáticos de cor e turbidez do Rio Taquaral, São Mateus do Sul. Após a caracterização da área, foram implantados ao longo do rio, quatro pontos de observação de dados pluviométricos e de coleta de água. As coletas foram submetidas à análise no laboratório da SANEPAR. Os resultados indicaram que na média, os índices de cor da água se apresentaram acima dos padrões da Resolução CONAMA 357/05. Já os de turbidez estavam dentro dos padrões dessa resolução. Estes se apresentaram mais elevados no alto curso, onde se pratica agricultura temporária e mecanizada.

Palavras- Chave: Bacia hidrográfica; Cor; Turbidez; Uso do solo.

\footnotetext{
${ }^{1}$ Mestre em Gestão do Território - UEPG. angelaewerling@yahoo.com.br

${ }^{2}$ Prof ${ }^{a}$ Dra. Em Geografia. Universidade Estadual de Ponta Grossa. ligialih@brturbo.com.br

${ }^{3}$ Prof ${ }^{\mathrm{a}}$ Dra. Em Química. Universidade Estadual de Ponta Grossa. ewscheffer@terra.com.br
} 


\section{ABSTRACT}

Human supply requires high quality water. In that sense, this article aims to relate the physical aspects, and land use with color indices and turbidity in the Taquaral watershed, Sao Mateus do Sul - PR. After characterize the area, it was implemented, along the river, four points of heeding the rainfall data and water samples. The samples was analyzed in the laboratory of SANEPAR. The results indicate that on average, color indices showed over that standards of the CONAMA Resolution 357/05. Since the turbidity indices, was according standards of this resolution. It was more elevated in the upper course, where farming is practiced temporary and mechanized.

Keywords: Watershed; Color; Turbidity; Land use.

\section{INTRODUÇÃO}

A combinação de fatores naturais e antrópicos interferem nas características e propriedades das águas, atribuindo-lhes caráter específico em cada lugar. Por vezes, essa interferência modifica as propriedades físicoquímicas e biológicas a ponto de comprometer a potabilidade, quando se trata de água destinada ao abastecimento público e outros usos também nobres.

A qualidade dos recursos hídricos destinados ao consumo humano tem dependido em grande parte dos sistemas de usos do solo nas encostas, associados aos processos erosivos que circundam as áreas de produção e de captação de água, dentro se uma dada bacia hidrográfica.

De modo geral, as águas doces são distribuídas em classes segundo a sua qualidade e destino, conforme Resolução CONAMA-357/05. A qualidade da água pode ser avaliada através de parâmetros específicos.

Do ponto de vista dos processos erosivos superficiais ou de canal fluvial, dois parâmetros são afetados de forma mais específica: cor e turbidez. Estes podem ser mensuráveis fisicamente, tratando-se então, de parâmetros físicos visíveis.

O tratamento da água sempre se inicia com a remoção dos materiais que flutuam ou estão suspensos nela. Assim sendo, são levados em consideração a interferência das diferentes formas de usos do solo e a relação destas com o processo erosivo, como indicador para explicar a origem do material em suspensão carreado pelo rio, processo do qual resultam os índices de parâmetros de cor e turbidez avaliados para esse trabalho. 
A produção de sedimentos está intimamente relacionada à composição, uso, manejo e transporte do elemento solo. Os sedimentos têm extrema importância em estudos de impacto ambiental, pelo que representa sua capacidade de acumular espécies de microorganismos e de elementos químicos que se associam ao material em suspensão, sendo transportados na forma dissolvida, ou por vezes, coloidal.

Levando-se em consideração que o montante de problemas causados pelos sedimentos e que sua produção e transporte estão diretamente relacionados com as vertentes das bacias hidrográficas, optou-se por esse recorte espacial como unidade de trabalho: a bacia hidrográfica do Rio Taquaral em São Mateus do Sul - PR. Essa bacia serve de captação de água para abastecimento da área urbana desse município, desde a década de 1.970 .

Tal contexto serve de justificativa para o desenvolvimento desse trabalho, cujo objetivo geral é investigar uma possível relação dos aspectos físicos e de uso do solo aos parâmetros de cor e turbidez da água do referido rio, à montante da estação de captação de água da Companhia de Saneamento do Paraná (SANEPAR).

\section{ÁGUA E O ABASTECIMENTO HUMANO}

Por vezes, as atividades antrópicas modificam as propriedades físicoquímicas e biológicas a ponto de comprometer sua potabilidade, quando se trata de água destinada ao abastecimento público e outros usos nobres. Para expressar de maneira simplificada a qualidade da água, bem como a sua potabilidade quando destinada ao uso humano, estabeleceu-se o Índice de Qualidade das Águas (IQA). Esse índice é usado por onze estados brasileiros, entre os quais o Paraná. (CETESB, 2010)

Em conformidade com a Resolução 357/05 do CONAMA, a CETESB aponta que tais parâmetros são "considerados relevantes para a avaliação da qualidade das águas, tendo como determinante principal a utilização das mesmas para abastecimento público”. (BRASIL, 2005).

De modo geral, as águas doces são distribuídas em classes segundo a 
sua qualidade e destino. A Resolução CONAMA- 357/05 apresenta em seu Capítulo II, Seção I, artigo 4ํㅜㄹ a distribuição dessas águas doces em quatro classes: Classes I, II e III, podem ser destinadas ao abastecimento humano após algum tipo de tratamento. Classe IV, podendo ser destinadas apenas para navegação e harmonia paisagística.

Para Raposo, Barros e Magalhães Júnior (2009, p.1):

um dos principais parâmetros de qualidade das águas capaz de demonstrar alterações na dinâmica hidrossedimentar de uma bacia como consequência da erosão acelerada é a turbidez. (...) Nesse sentido, a turbidez é muito útil em análises ambientais em bacias hidrográficas, uma vez que é possível associar o uso e cobertura do solo a este parâmetro, a fim de se detectar danos nos cursos d'água relacionados a atividades humanas por exemplo.

Os padrões de qualidade da água doce para consumo humano, relativos aos parâmetros cor e turbidez apresentam-se assim distribuídos:

Tabela 1 - Parâmetros de cor e turbidez de acordo com as classes da água, definidos pela Resolução CONAMA 357/05.

\begin{tabular}{c|l|l}
\hline CLASSE & \multicolumn{1}{|c|}{ COR } & TURBIDEZ \\
\hline $\mathrm{I}$ & $\begin{array}{l}\text { Nível de cor natural do corpo de } \\
\text { água em mgPt/L }\end{array}$ & Até 40 UNT \\
$\mathrm{II}$ & Até $75 \mathrm{mgPt} / \mathrm{L}$ & Até $100 \mathrm{UNT}$ \\
$\mathrm{III}$ & Até $75 \mathrm{mgPt} / \mathrm{L}$ & Até $100 \mathrm{UNT}$ \\
\hline
\end{tabular}

Fonte: Resolução CONAMA 357/05. Disponível em: < http://www.mma.gov.br>. Acesso em 03 jun. 2010.

De acordo com a Portaria 518/04 do Ministério da Saúde (BRASIL, 2004), a água potável deve estar em conformidade com o padrão de aceitação para consumo humano. Esse estabelece valor máximo permitido para cor, de $15 \mathrm{uH}^{4}$, e para turbidez, um valor de no máximo $5 \mathrm{NTU}^{5}$.

Segundo Macêdo (2001), todas as impurezas da água (exceto os gases dissolvidos) contribuem para a carga de sólidos, que por sua vez, podem ser classificados conforme seu tamanho e características químicas. Aos materiais em suspensão, somam-se bactérias, algas e protozoários, e o iodo, por

\footnotetext{
${ }^{4} \mathrm{uH}$ - Unidade Hazen (mgPtCo/l): 1 miligrama de platina por litro de água na forma de hexacloroplanitato.

2 UNT /NTU - Unidade Nefelométrica de Turbidez: Unidade de Turbidez em mg/l de sílica.
} 
exemplo.

\section{MATERIAL E MÉTODOS}

\section{ÁREA DE ESTUDO}

A bacia hidrográfica do rio Taquaral (Figura 1) situa-se na porção leste da área urbana do município de São Mateus do Sul, que ocupa a porção sudeste do Paraná. A bacia, possui $112,830 \mathrm{Km}^{2}$ e ocupa $8 \%$ do município. (IPARDES, 2008).

O Rio Taquaral, cujas nascentes situam-se a aproximadamente $904 \mathrm{~m}$ de altitude, que corresponde a parte mais alta do município, percorre, em seu médio e alto curso, área rural, destinada a produção de fumo, milho, soja, feijão, batata e criação de animais em pequenas e médias propriedades. Em seu baixo curso percorre a porção leste da área urbana do município, tendo sua foz na cota de $759 \mathrm{~m}$ de altitude.

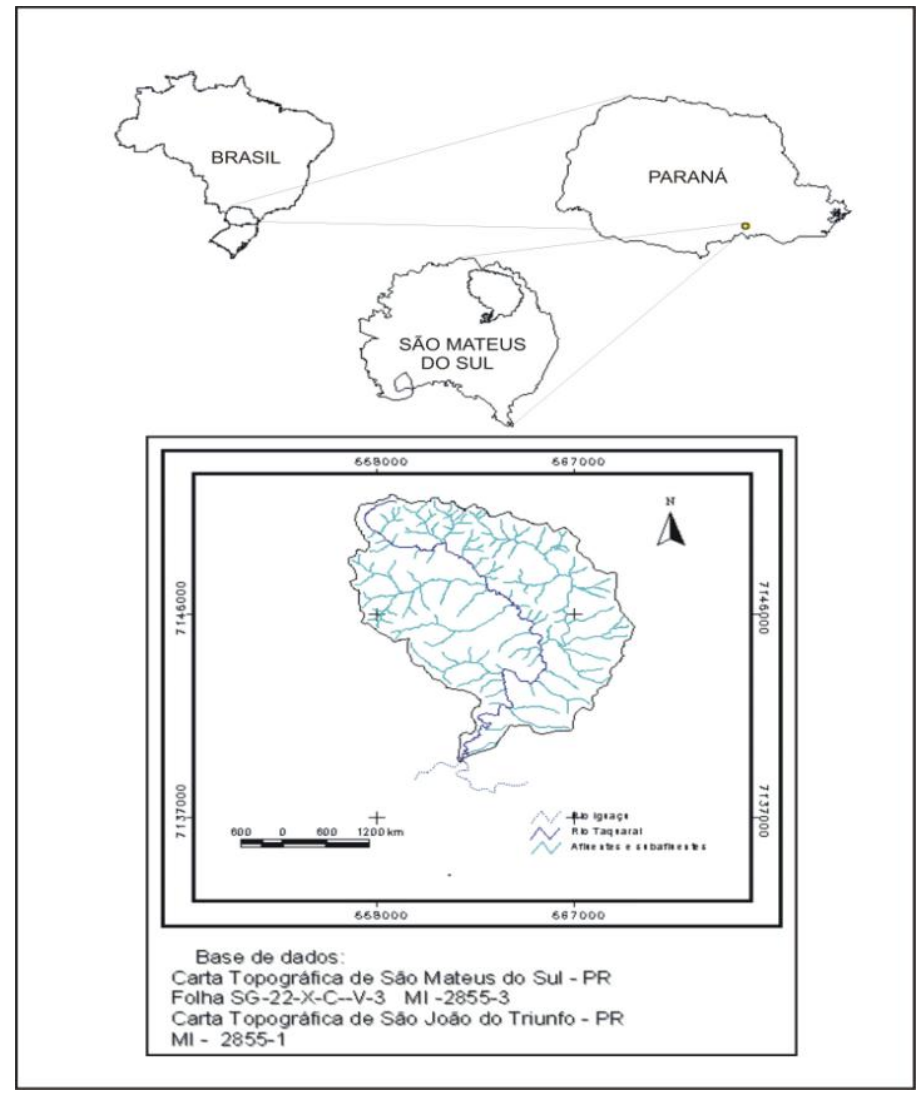

Figura 1 - Localização da Bacia Hidrográfica do rio Taquaral -São Mateus do Sul/PR Org.: A autora 
Regionalmente, a área de estudo se localiza na subunidade morfoescultural, do Planalto de São Mateus do Sul (MINEROPAR, 2006), domínio morfoestrutural da Bacia Sedimentar do Paraná.

Morfologicamente, o município apresenta dissecação baixa e um gradiente de 240 metros com altitudes variando entre 760m (mínima) e 1.000m (máxima). A classe de declividade predominante é menor que $6 \%$ em uma área de $1.063,54 \mathrm{~km}^{2}$. As formas de relevos apresentam, predominantemente, topos aplainados, vertentes retilíneas e vales em "V", modeladas em rochas das Formações Teresina, Palermo, Rio Bonito e Serra Alta. (MINEROPAR, 2006).

Geologicamente, na região, o Segundo Planalto Paranaense é constituído por sedimentos da era Paleozóica, destacando-se cordões carboníferos e xisto betuminoso, com afloramentos de rochas vulcânicas, fator esse que o torna a mais rica região do Estado em recursos minerais, como por exemplo, o calcário, areia e xisto betuminoso. A porção sedimentar é constituída quase na sua totalidade de terrenos pertencentes à Bacia Sedimentar do Paraná. (MINEROPAR, 2006).

A área deste estudo se inclui em terrenos das unidades litoestratigráficas: Formação Rio Bonito (Prb), Formação Palermo (Pp), ambas do Grupo Guatá/Permiano-Devoniano, e Formação de Sedimentos Recentes (Qha) do Quaternário Holoceno. Em seu alto curso ocorre a Formação Palermo, sendo possível constatar a presença de uma falha definida. Nos cursos médio e inferior do Rio Taquaral, podem ser encontradas rochas da formação Rio Bonito, em que se registram falha preenchida por dique e áreas de contato aproximado entre as duas formações citadas. Coincide que nas áreas onde se localizam as falhas, o rio apresenta trechos do seu canal, controlados por essas estruturas. Junto à sua foz no Rio Iguaçu, registra-se a ocorrência da Formação de Sedimentos Recentes.

Essas rochas, pela presença de descontinuidade, são susceptíveis à ação do intempirismo químico e de processos erosivos, sendo as rochas de origem cristalina, mais resistentes ao processo erosivo pela água, que as rochas sedimentares. 
As condições climáticas podem influenciar no processo erosivo de várias formas, sendo a chuva o agente erosivo mais comum na área de estudo. Além desse, contribuem para tal processo, fatores climáticos como a temperatura e as massas de ar que ali atuam.

Conforme Maack (1981, p. 89) sobre o clima no Estado do Paraná, este afirma que a "maior parte do Estado está inserida na zona subtropical, entre $23^{\circ} 27^{\prime}$ e $26^{\circ} 47^{\prime \prime}$. Na região onde se situa a Bacia Hidrográfica do Taquaral, predominam climas temperados ou subtropicais úmidos, com uma média de aproximadamente $1558,7 \mathrm{~mm}$ de chuvas bem distribuídas ao longo do ano, se considerado o período entre 2000 e 2009 (COPEL, 2009).

Dependendo das variáveis climáticas e das propriedades do solo, a este são aplicadas medidas de manejo e ainda de controle da erosão. Associa-se a suas características de textura, porosidade, permeabilidade, fatores como topografia, clima e cobertura do solo como elementos que influenciam na resistência ao processo erosivo.

Em termos de solo, predominam na área de estudo, solos como o Cambissolo Háplico associado ao Neossolo Litólico, Latossolo Vermelho e a Associação Latossolo Vermelho com Nitossolo Háplico (EMBRAPA, 1984). Genericamente, os Cambissolos são pouco profundos, com baixa permeabilidade e um horizonte $B$ incipiente $(10 \mathrm{~cm}$ de espessura), textura argilosa, estando assim mais susceptíveis à erosão. Os latossolos também apresentam textura argilosa, porém se caracterizam por serem mais profundos, porosos, bem drenados e permeáveis. Os Latossolos Vermelhos e Associação Cambissolo Háplico/Neossolo Litólico estão distribuídos quase que totalmente dentro da formação geológica Pp - Formação Palermo. Na área de Associação Latossolo Vermelho com Nitossolo Háplico, tem-se como base a Formação Prb- Rio Bonito.

No interior da bacia do Taquaral, predominam os latossolos, menos suscetíveis aos processos erosivos. Estabelecendo uma análise em relação aos elementos já descritos - como o relevo suave ondulado e os solos que a esse se associam - é possível afirmar que tal condição favorece a instalação de agricultura com uso de máquinas. 
As condições pedomorfológicas e climáticas são favoráveis para 0 desenvolvimento de determinadas formações arbóreas e herbáceas. Encontrase no Manual Técnico da Vegetação Brasileira (IBGE, 1992) a caracterização da vegetação referente à área desse estudo, onde estão presentes de forma predominante a Floresta Ombrófila Mista Montana e a formação de Vegetação Secundária. Ainda de acordo com o IBGE, a área de estudo em questão se enquadra como pertencente ao Bioma Mata Atlântica.

A Floresta Ombrófila Mista Montana, apresenta-se bastante devastada pelos usos da terra, restando apenas alguns remanescentes. O extrativismo vegetal, seguido da pecuária e uso agrícola, descaracterizou a vegetação original. Nos fragmentos abandonados por essas atividades ocorrem a formação de Floresta Secundária.

Tal formação vegetal segundo Maack (1981) ocupa a maior porção de todos os planaltos de vegetação de regeneração.

No seu baixo curso, destaca-se a distinção em relação à ocupação da área da bacia, que além de florestas e áreas de agropecuária, conta com a ocupação de área urbana.

\section{METODOLOGIA}

A metodologia aplicada no desenvolvimento desse trabalho deu-se a partir de leituras para embasamento teórico e produção textual, elaboração de base cartográfica em laboratório e atividades de campo.

Os levantamentos de dados em campo, foram realizados a partir de observações e registro de índices de pluviosidade e coleta de água em 4 pontos da Bacia Hidrográfica do Taquaral (Figura 2). Estes pontos se justificam em função dos diferentes usos do solo e setores do rio, sendo as coletas, realizadas no $15^{\circ}$ dia de cada mês e a cada precipitação igual ou superior 25 mm num período de 12 horas, de chuvas de evento contínuo. As coletas feitas no $15^{\circ}$ dia de cada mês tiveram por objetivo, acompanhar o estado regular da cor e turbidez da água.

Hudson (1973 apud LOMBARDI NETO; MOLDENHAUER,1992) em observação sobre energia cinética de chuvas individuais na África Subtropical, 
constatou que chuvas superiores a $25,4 \mathrm{~mm}$ apresentaram estreita relação com perda de solo. Estudos de Lombardi Neto e Moldenhauer (1992) em Campinas - São Paulo, sobre o mesmo assunto, usaram como parâmetro, chuvas superiores e inferiores a $10 \mathrm{~mm}$, levando em conta a quantidade total, a duração, a energia cinética e a intensidade máxima de 30 minutos.

Tomando por referencial a possibilidade considerada por Hudson e a observação das médias diárias de pluviosidade dos últimos 5 anos na área de estudo em questão, considerou-se o valor de $25 \mathrm{~mm}$ de evento pluviométrico contínuo para a realização de coletas de água. Além desses elementos, levouse em conta que o potencial de erosão de uma chuva está atrelado a fatores como tipo de solo, forma de uso do solo, declive da encosta e das características da chuva. Houve a preocupação ainda, quanto à viabilidade de realizar a coleta em cada ponto estabelecido para cada chuva segundo o critério adotado. Assim, foram feitas comparações das taxas de cor e turbidez de dias sem chuvas (coletas $15^{\circ}$ dia do mês) e com chuvas iguais ou superiores a $25 \mathrm{~mm}$. Chegou-se à conclusão que há uma presença significativa de sedimentos na água em chuvas iguais ou superiores a $25 \mathrm{~mm}$, 0 que justifica o uso de tal valor.

Os pontos de coleta (figura 2) foram assinalados sobre a carta topográfica de São Mateus do Sul, em escala 1: 50.000, da Diretoria de Serviço Geográfico (DSG) do Exército, 2006. No programa de software ArcView 3.2a foi traçado o limite da Bacia Hidrográfica do Taquaral, sua rede hidrográfica de acordo com a hierarquia de Strahler, e calculadas as métricas apresentadas na sequência desse estudo, com o objetivo de caracterizar a bacia hidrográfica.

Primeiro ponto de coleta: Alto Curso do Rio Taquaral (2546'S; 50²3’W)

Localidade: Taquaral do Bugre

Segundo ponto de coleta: Alto Curso do Rio Taquaral $\left(25^{\circ} 47^{\prime} \mathrm{S}\right.$; $\left.50^{\circ} 21^{\prime} \mathrm{W}\right)$

Localidade: Faxinal dos Ilhéus

Terceiro ponto de coleta: Foz do Rio do Meio no Rio Taquaral (2549'S; $\left.50^{\circ} 20^{\prime} \mathrm{W}\right)$

Localidade: Espigãozinho

Quarto ponto de coleta: Baixo Curso do Taquaral $\left(25^{\circ} 52^{\prime} \mathrm{S} ; 50^{\circ} 22^{\prime} \mathrm{W}\right)$ 
Localidade: Área Urbana de São Mateus do Sul - Usina Velha.

O primeiro ponto de coleta é definido em função do segmento do rio, alto curso, e a ocupação da área se caracterizar pelo predomínio de pequenas propriedades agrícolas, dedicadas ao cultivo de fumo, soja, feijão e milho. A esses cultivos estão incorporados o uso de máquinas e a prática de plantio direto. Tal prática permite que parte do ano o solo fique mais exposto, o que implica numa capacidade maior de transporte de sedimentos pelas águas das chuvas; ocasionando por sua vez, alteração nos parâmetros de cor e turbidez.

Considera-se que o segundo ponto de coleta é estratégico pelo fato de que ali o Taquaral já conta com a carga de um importante tributário da sua margem direita, o Rio Sanga Funda. Este percorre áreas de grandes propriedades que cultivam batata e também desenvolvem a suinocultura.

O terceiro ponto de coleta se define por ser um importante afluente da margem esquerda do Rio Taquaral: o Rio do Meio; cuja bacia tem seus cursos em áreas de propriedades agrícolas de pequeno e médio porte, cuja bacia é drenada em áreas agrícolas de pequeno e médio porte, com culturas permanentes e temporárias destinadas para comercialização, como pinus, fumo e erva-mate.

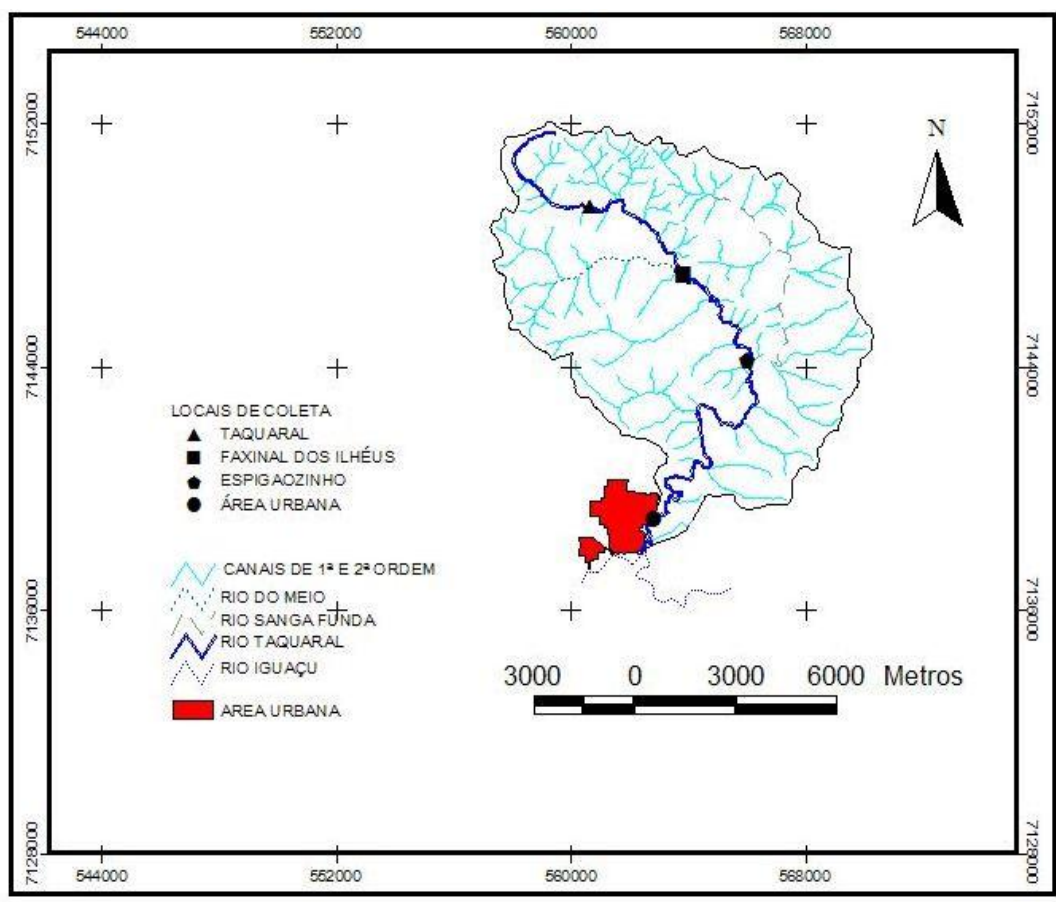

Figura 2 - Localização dos Pontos de Coleta de Água e apresentação da Hierarquia Fluvial da Bacia Hidrográfica do Taquaral. Org.: A autora 
A definição do quarto ponto usa como critério a possibilidade de neste local observar-se a influência da área urbana em relação à quantidade de sólidos suspensos carreados pelo Taquaral. Localizado junto à parte leste da área urbana, na Usina Velha, observa-se a ocupação de áreas de risco e de manancial, produção de sedimentos por estradas sem pavimento, terreno declivoso e impermeabilização do solo, que aceleram o escoamento superficial e transporte de sedimentos, influenciando diretamente na cor e turbidez da água.

Em cada um desses pontos foi instalado um pluviômetro com capacidade $150 \mathrm{~mm}$, com escala de $2 \mathrm{~mm}$ (modelo 4749 - INCOTERM). O registro da pluviosidade foi realizado às 06 horas e 18h. A soma dos milímetros no intervalo de 12 horas durante o dia, ou da noite em relação à manhã, perfazendo $25 \mathrm{~mm}$ ou mais de chuva de evento contínuo, implicou na coleta de água, que serviu de amostra para ser analisada quanto à cor e turbidez, no laboratório da SANEPAR. Estas não precisaram ser submetidas à análise em curto intervalo de horas, desde que armazenadas em lugar cujas condições de temperatura amena $\left(18^{\circ} \mathrm{C}\right)$, em local fresco e arejado. As análises laboratoriais de todas as coletas foram realizadas entre $016^{\circ}$ e $20^{\circ}$ dia de cada mês.

A coleta foi feita com um coletor construído a partir de uma garrafa PET de 2 litros, fixa a uma haste e com um suspiro de saída de ar. A coleta é feita no meio do canal, no seu talveg, a uma profundidade média de $10 \mathrm{~cm}$.

No laboratório da SANEPAR utilizou-se entre 200 a $250 \mathrm{ml}$ da amostra para procedimentos de ambientação e análise. O teste de cor foi feito através do método de comparação por disco, empregando-se um disco Aqua Tester marca d Tomé.

Dependendo da intensidade da cor da água in natura realiza-se diluição da amostra com água destilada, aplicando-se o fator de diluição 10:100.

A análise de turbidez foi realizada através de um turbidímetro digital Hach, modelo 2100P, sendo a unidade empregada NTU/UNT (Unidades Nefelométrica de Turbidez).

Ainda no $15^{\circ}$ dia de cada mês, paralelo a coleta foi realizada uma observação detalhada em relação a aspectos ligados à dinâmica fluvial. 
Em cada ponto de coleta, calculou-se um raio aproximado de $500 \mathrm{~m}$ à montante do local de coleta, para observar clinicamente e registrar com fotografias, a manifestação de processos erosivos da margem do canal. A observação consistiu em registrar as mudanças no entorno e ainda em relação ao uso do solo, como uso para culturas permanentes ou temporárias, terras preparadas para cultivo antes de precipitação, avanço da ocupação na área urbana entre outros eventos possíveis de acontecerem.

\section{RESULTADOS}

Pode-se definir a partir da metodologia proposta por Strahler, que o Rio Taquaral é de 4⿳亠丷a ordem, numa escala 1:50.000, como demonstrado na Figura 4; tendo sua bacia um perímetro de $52,138 \mathrm{~km}$ e uma área de 112,830 km².

Sabendo-se a hierarquia fluvial de uma bacia hidrográfica é possível estimar o número de rios que a compõem pela "lei do número de canais". $\mathrm{Na}$ metodologia de Strahler (1952 apud CHRISTOFOLETTI, 1980) a ordem de um canal aumenta de 1 na medida em que este entra em confluência com outro de mesma ordem, sendo o número total de canais correspondente ao número de canais de $1^{\text {a }}$ ordem.

O rio principal foi definido a partir do critério de Horton (1945), em que "o canal de ordem mais elevada corresponde ao rio principal", ou ainda pelo critério de Shreve (1974 apud CHRISTOFOLETTI, 1980, p.111): "curso de água mais longo, da desembocadura da bacia até determinada nascente, medido como a soma dos comprimentos dos seus ligamentos". Desta forma, é possível afirmar que o rio principal apresenta $30,058 \mathrm{~km}$ de comprimento, com uma amplitude altimétrica de 145 metros, sendo esta considerada como a diferença entre o ponto mais elevado e a desembocadura do canal principal.

A bacia hidrográfica apresenta um Índice de Circularidade 0,521. Esse número representa segundo Granell-Pérez (2004), um alto risco de enchentes súbitas no canal principal, diante de uma precipitação intensa em toda a extensão da bacia hidrográfica. Tal fenômeno se explica pela grande quantidade de água de chuva das vertentes e dos afluentes que irão convergir num curto espaço de tempo para o canal principal, ocasionando um pico de 
vazão. Devido a essas condições, é mais adequado que sejam mantidas o maior número de áreas com cobertura vegetal e práticas de conservação de solo para assim, facilitar a infiltração, controlando o escoamento superficial associado à capacidade de erodir os solos.

A densidade de rios está vinculada ao clima da região. Dependendo dos índices anuais de pluviosidade, os rios podem ser perenes ou temporários. Com uma pluviosidade média de aproximadamente $1.558 \mathrm{~mm}$ anuais bem distribuídos, os rios locais são perenes. Para se chegar à densidade de rios relação existente entre o número de rios e a área da bacia - com a finalidade de comparar a quantidade de cursos de água por quilômetro quadrado, aplicase a fórmula Horton (1945 apud CHRISTOFOLETTI, 1980). Nesse caso, o número obtido foi 1,019. A densidade de rios indica a disponibilidade de água na bacia. Associando esse resultado ao fato de que os rios são perenes, é possível afirmar que a disponibilidade de água nessa bacia é boa dentro de padrões normais de pluviosidade.

A densidade de drenagem, definida pelo mesmo autor, correlaciona 0 comprimento total dos canais de escoamento com a área da bacia hidrográfica, a partir da equação que divide o comprimento total de canais $(178 \mathrm{~km})$ pela área da bacia $\left(112,830 \mathrm{~km}^{2}\right)$; tendo como resultado o valor 1,57.

Segundo Christofoletti (1969) valores abaixo de $7,5 \mathrm{~km} / \mathrm{km}^{2}$ representam baixa densidade de drenagem, parâmetro que permite inferir então, que essa é a característica da bacia hidrográfica do Taquaral. De acordo com GranellPérez (2004), esse valor de baixa densidade de drenagem, é um indicativo de que na bacia em questão, têm-se solos com boa infiltração, boa cobertura vegetal e relevo suave. Essas características se confirmam, por exemplo, na área de maior altitude. Ali se registra a predominância do solo latossolo vermelho, com boa condição de permeabilidade e assim, controle maior de agentes erosivos, diminuindo a capacidade de transportar sedimentos a serem carreados.

Aos dados já apresentados, acrescentam-se os valores 9,99\% de declividade média $(H)$ e 15,84 de coeficiente de rugosidade (RN) para a bacia desse estudo. Para calcular a declividade, multiplica-se o total de quilômetros 
das curvas de nível pela equidistância em quilômetros das curvas de nível. 0 valor obtido deve ser dividido pela área da bacia e então, multiplicado por 100. O coeficiente de rugosidade é obtido pelo cálculo que multiplica o valor da densidade de drenagem pelo valor da declividade média. (GRANELL-PÉREZ, 2004)

Relacionam-se esses valores ao que a mesma autora, explica sobre tais parâmetros: a declividade média da bacia $(\mathrm{H})$ e o coeficiente de rugosidade (RN) são dois parâmetros significativos de indicadores de riscos na bacia. $A$ declividade se correlaciona com a energia do relevo, determinando a capacidade que este apresenta na velocidade dos fluxos hídricos superficiais e infiltração.

Logo, terrenos de relevo com menor energia, como no caso dessa bacia, apresentam uma velocidade menor do escoamento hídrico devido a gravidade. O mesmo critério se aplica ao coeficiente de rugosidade, ou seja, quanto menores os seus valores, menores os riscos de erosão por processos hídricos.

A intervenção antrópica de forma mais expressiva da região da Bacia Hidrográfica do Taquaral, teria se dado a partir de 1890, quando do início da povoação da área com a chegada de imigrantes. Chefiados por Sebastião Edmundo Saporski, chegaram os poloneses em número de duas mil famílias, estabelecendo-se nas colônias Iguaçu, Canoas, Cachoeira, Taquaral do Bugre, Água Branca e Rio Claro. (SÃO MATEUS DO SUL, 2011).

No início a economia da colônia baseava-se na agricultura e no extrativismo, principalmente da madeira e da erva-mate, principais riquezas da região.

A partir da década de 1930, as formações nativas são significativamente alteradas pelo desmatamento e ocupação dessas áreas para formação de roça.

Através de levantamento de dados em campo, é possível contatar que atualmente, a região é ocupada predominantemente por pequenos e médios proprietários que se dedicam principalmente ao cultivo de fumo, milho, soja, e criação de animais em pequena escala, entre os quais merece destaque a suinocultura. 
Essa característica de estrutura fundiária se associa ao desmatamento, onde muitos proprietários o justificam pela pequena extensão da propriedade, havendo assim que aproveitar o máximo para produção. Em áreas de grandes propriedades, que representam a minoria, é o cultivo de feijão e batata que predominam, além da silvicultura.

Junto à margem direita do curso inferior da bacia do Taquaral, tem-se a ocupação do espaço pelo processo desordenado de urbanização. Dados levantados em campo permitem afirmar que esse processo tem avançando significativamente nas áreas de manancial, na Área de Preservação Permanente (APP), principalmente junto à área denominada "Usina Velha".

Esse quadro de ocupação urbana desordenada soma-se a fatores como declividade do terreno, resíduos da construção civil, erosão de estradas sem pavimento e lixo residencial em sua forma de efluentes sólidos e líquidos lançados nesse rio, à jusante da captação de água para abastecimento da população.

Com relação aos parâmetros aquáticos determinados, os dados obtidos (Tabela 2) indicam que as amostras de água coletadas no Ponto 1, nos dias em que ocorreu chuva igual ou superior a $25 \mathrm{~mm}$, apresentam maior turbidez em relação aos demais locais de amostragem, de modo particular, em relação ao Ponto 4, localizado à jusante do rio e que é muito próximo ao ponto de captação de água da SANEPAR.

A maior turbidez verificada indica presença mais expressiva de materiais finos em suspensão na água. A carga maior de sedimentos transportados para o canal do rio principal no Ponto 1, provém de uma área onde predominam as maiores altitudes da bacia, com Latossolo Vermelho e Associação Cambissolo Háplico/Neossolo Litólico. Nesta área, o uso do solo se caracteriza pela agricultura temporária com uso de máquinas.

Por outro lado, o Ponto 4 está nas menores altitudes, com Latossolo Vermelho, onde o uso do solo se dá através de pastagem na margem esquerda e área urbana na margem direita. Essa caracterização pode ser um dos elementos que explica parte da diferença no processo de transporte de sedimentos. 
Outro fator que pode explicar essa diferença dos valores de turbidez entre os Pontos 1 e 4, é a baixa energia do relevo. Ao longo de $30.058 \mathrm{~km}$ de rio, o relevo apresenta uma diferença altimétrica de $145 \mathrm{~m}$, o que não é significativo. Associado a essa característica de baixa energia de relevo, o canal do rio apresenta-se mais estreito no curso superior e se alarga ao longo dos cursos médio e baixo, com certo grau de sinuosidade. Esses fatores propiciam uma maior deposição de sedimentos ao longo do curso, impedindo assim que a carga gerada no alto curso chegue até à jusante.

Após período de estiagem de aproximadamente 40 dias, pode-se observar uma variação significativa na turbidez e cor no Ponto 4, fato que pode ser atribuído a maior contribuição de sedimentos carreados pelo uso da terra na área urbana.

A frequência das chuvas não alterou os índices de turbidez e cor junto ao ponto de Captação de água da SANEPAR, mantendo-se na média, dentro dos padrões da RESOLUÇÃO CONAMA 357/05. Esta característica indica boa qualidade da água representando um ônus menor no processo de tratamento da água a ser disponibilizada para o consumo humano.

A cor verificada nas amostras, em períodos sem chuva, se apresenta constante em todos os pontos de coleta. Já com chuva, dentro dos níveis de pluviosidade estabelecidos nessa pesquisa, para realização de coleta, há uma variação maior no ponto 1 em relação aos demais, ficando acima dos padrões da Água Doce Classe III - Resolução 357/05 (CONAMA), o que indica uma taxa elevada de substâncias dissolvidas.

Essa mesma resolução estabelece o valor máximo de $75 \mathrm{mgPt} / \mathrm{l}$ para cor de águas de Classe II e III. Observa-se que nos dias em que ocorreu chuva igual ou superior a $25 \mathrm{~mm}, 70 \%$ das amostras analisadas, apresentaram valores bem acima desse limite estipulado na legislação vigente. Tal fato pode indicar restrições ao uso devido à perda de qualidade, exigindo ainda aumento de custos no seu processo de tratamento para consumo humano.

Em relação às chuvas, pode-se observar variação de volume e do período do dia em que ocorrem, quando comparados os pontos de coleta. Essa variação ocorre em ambos os aspectos entre os Pontos 1 e 2 em relação aos 
Pontos 3 e 4, o que pode ser determinante na comparação dos valores de cor e turbidez se as coletas forem realizadas simultaneamente no mesmo horário nos 4 pontos. Há que se considerar também, a distribuição das chuvas no período estabelecido de 12 horas. O fato de serem chuvas calmas e bem distribuídas ou de serem pancadas fortes e concentradas pode gerar alterações relevantes nas concentrações obtidas. 
Tabela 2 - $\quad$ Dados de turbidez, cor e pluviosidade, coletados entre $1^{\circ}$ de Agosto de 2010 a 30 de Outubro de 2010.

\begin{tabular}{|c|c|c|c|c|c|c|c|c|c|}
\hline PONTO/PARÂMETRO & $\begin{array}{l}\text { COLETA } 1 \\
4 / 8 / 2010 \\
\end{array}$ & $\begin{array}{c}\text { COLETA } 2 \\
15 / 8 / 2010 \\
\end{array}$ & $\begin{array}{c}\text { COLETA } 3 \\
15 / 9 / 2010 \\
\end{array}$ & $\begin{array}{c}\text { COLETA } 4 \\
24 / 9 / 2010 \\
\end{array}$ & $\begin{array}{c}\text { COLETA } 5 \\
2 / 10 / 2010 \\
\end{array}$ & $\begin{array}{l}\text { COLETA } 6 \\
5 / 10 / 2010 \\
\end{array}$ & $\begin{array}{c}\text { COLETA } 7 \\
7 / 10 / 2010 \\
\end{array}$ & $\begin{array}{l}\text { COLETA } 8 \\
15 / 10 / 2010 \\
\end{array}$ & $\begin{array}{l}\text { COLETA } 9 \\
30 / 10 / 2010 \\
\end{array}$ \\
\hline \multicolumn{10}{|l|}{ TURBIDEZ (UNT) } \\
\hline \multirow[t]{2}{*}{ PONTO 1} & 141 & 8,65 & 5,27 & 37,4 & 40,3 & 46,5 & 59,9 & 19,1 & 55,8 \\
\hline & $30 \mathrm{~mm}$ & & & $25 \mathrm{~mm}$ & $40 \mathrm{~mm}$ & $26 \mathrm{~mm}$ & $25 \mathrm{~mm}$ & $28 \mathrm{~mm}$ & $45 \mathrm{~mm}$ \\
\hline \multirow[t]{2}{*}{ PONTO 2} & & 9,29 & 1,78 & 21,9 & 26,8 & 65,7 & 22,2 & 16,3 & 61,3 \\
\hline & & & & $26 \mathrm{~mm}$ & $38 \mathrm{~mm}$ & $26 \mathrm{~mm}$ & $25 \mathrm{~mm}$ & $25 \mathrm{~mm}$ & $46 \mathrm{~mm}$ \\
\hline \multirow[t]{2}{*}{ PONTO 3} & 65,8 & 11,4 & 2,09 & & 15,9 & & & 13,6 & 6,55 \\
\hline & $29 \mathrm{~mm}$ & & & & $32 \mathrm{~mm}$ & & & $25 \mathrm{~mm}$ & $50 \mathrm{~mm}$ \\
\hline \multirow[t]{2}{*}{ PONTO 4} & 25,3 & 10,7 & 3,42 & & 34,1 & & & 13,1 & 5,88 \\
\hline & $30 \mathrm{~mm}$ & & & & $32 \mathrm{~mm}$ & & & $37 \mathrm{~mm}$ & $50 \mathrm{~mm}$ \\
\hline \multicolumn{10}{|l|}{$\operatorname{COR}(\mathrm{uH})$} \\
\hline PONTO 1 & 175,0 & 20,0 & 25,0 & 100,0 & 125,0 & 225,0 & 225,0 & 50,0 & 100,0 \\
\hline PONTO 2 & & 20,0 & 20,0 & 100,0 & 100,0 & 275,0 & 175,0 & 50,0 & 100,0 \\
\hline PONTO 3 & 100,0 & 25,0 & 25,0 & & 100,0 & & & 50,0 & 12,5 \\
\hline PONTO 4 & 50,0 & 25,0 & 25,0 & & 125,0 & & & 50,0 & 10,0 \\
\hline
\end{tabular}

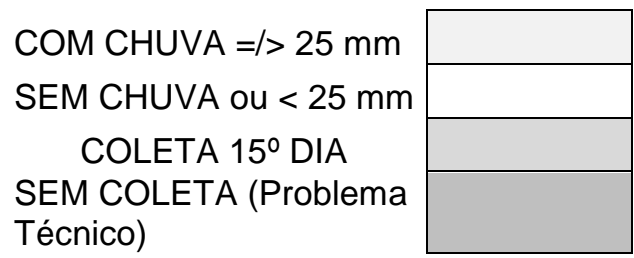

Fonte: Laboratório da SANEPAR. 


\section{CONSIDERAÇÕES FINAIS}

A localização da Bacia Hidrográfica do Taquaral permite observar que, do ponto de vista do abastecimento humano, é a fonte mais importante do município de São Mateus do Sul.

Morfometricamente o Rio Taquaral é de $4^{\mathrm{a}}$ ordem, a partir dos pressupostos de Strahler (1952), na escala 1:50.000.

Pela verificação dos resultados da análise da água, percebeu-se que a capacidade no transporte de sedimentos em suspensão, se apresenta de forma distinta ao longo da bacia. Esse fato pode ser verificado a partir das características do relevo, solos, canal principal, pluviosidade e de uso da terra.

A princípio, os índices mais elevados de turbidez, nos pontos 1 e 2, podem ser explicados pelo uso do solo para agricultura temporária e mecanizada nas áreas de maior declividade da bacia. Considera-se que até 0 ponto 1, o rio Taquaral ainda é um rio de $3^{\text {a }}$ ordem, contando com pouco volume de água, dificultando assim a dispersão dos sedimentos.

Os rios da bacia apresentam em boa parte ao longo de seus cursos, as formações Floresta Ombrófila Mista Montana e de Vegetação Secundária. Essas exercem função ecológica em seu aspecto mais amplo, e de forma específica, no sentido de conter uma carga maior de sedimentos que possam ser carreados aos canais fluviais.

Pode-se inferir ainda, que a partir do local em que o rio Taquaral passa a ser de $4^{\text {a }}$ ordem, verifica-se um controle estrutural, acompanhado de dique no sentido noroeste-sudeste. Um controle estrutural pode ser conferido ainda, no seu médio e baixo curso. Ali se verifica um alinhamento no sentido nordeste-sudoeste. Tais controles estruturais podem ser a explicação para a mudança de direções que o curso do rio apresenta no seu alto curso em relação ao baixo curso.

É nas vertentes das bacias que pode ser feito o controle da carga de sedimentos em suspensão possíveis de serem erodidos; que podem interferir na cor e turbidez da água, podendo-se assim, obter melhores resultados no manejo e planejamento dos recursos hídricos.

As informações constantes nesse estudo permitem ampliar as discussões sobre os resultados aqui apresentados, bem como a busca de um 
maior número delas. Trata-se da bacia de captação de água para abastecimento humano da cidade e parte da área rural de São Mateus do Sul, e que até o presente momento, apresenta uma escassez de informações sistematizadas disponibilizadas ao público. Portanto, esse estudo pode contribuir para novos trabalhos de morfometria da bacia hidrográfica do Taquaral, e também para gestão e planejamento ambiental dos recursos hídricos.

\section{REFERÊNCIAS}

BRASIL. Ministério da Saúde. Portaria MS no 518, de 25 de março de 2004. Estabelece os procedimentos e responsabilidades relativos ao controle e vigilância da qualidade da água para consumo humano e seu padrão de potabilidade, e dá outras providências. Disponível em: < http://dtr2001.saude.gov.br>. Acesso em: 03 jun. 2010.

BRASIL. Conselho Nacional de Meio Ambiente. Resolução no 357 de 17 de março de 2005. Dispõe sobre a classificação dos corpos de água e diretrizes ambientais para o seu enquadramento, bem como estabelece as condições e padrões de lançamento de efluentes, e da outras providências. Disponível em: $<$ http://www.mma.gov.br>. Acesso em 03 jun. 2010.

BRASIL. Ministério da Defesa. Diretoria do Serviço Geográfico Brasileiro. Carta Topográfica de São Mateus do Sul. Porto Alegre, 2006.

CHRISTOFOLETTI, A. Análise morfométrica de bacias hidrográficas. Revista Geomorfologia. Campinas: v 18,n9,p. 35-64, 1969.

A. Geomorfologia. São Paulo: Edgard Blucher, 2ª edição,

1980. $188 p$.

Empresa Brasileira de Pesquisa Agropecuária (EMBRAPA) SNLCS/SUDESUL/IAPAR. Levantamento de Reconhecimento dos Solos do Estado do Paraná. Londrina: EMBRAPA/IAPAR, 1984, 791p.

GRANELL-PÉREZ, M. Del C. Trabalhando Geografia com as Cartas Topográficas. 2ed. ljuí: Ed.Uniljuí, 2004, 128p.

Instituto Brasileiro de Geografia e Estatística (IBGE). Manual Técnico da Vegetação Brasileira. Rio de Janeiro: 1992.91p.

Instituto Brasileiro de Geografia e Estatística (IBGE). Censo Demográfico 2010. Disponível em: <www.ibge.gov.br>. Acesso em: 12 jan. 2011. 
Instituto Paranaense de Desenvolvimento Econômico e Social (IPARDES). Caderno Estatístico de São Mateus do Sul. Disponível em: <www.ipardes.gov.br/cadernos>.Acesso em: 07 Nov. 2010.

LOMBARDI NETO, F; MOLDENHAUER, W. Erosividade da chuva: sua distribuição e relação com perdas de solo em Campinas, SP. Bragantia, Campinas, 51(2):189-196, 1992.

MAACK, R. Geografia Física do Paraná. 2 ed. Rio de Janeiro: J. Olympio; Curitiba: Secretaria da Cultura e do Esporte do Governo do Estado do Paraná, 1981. 450p.

MACÊDO, J.A.B. Águas \& águas. São Paulo: Varela, 2001, 505p.

Minerais do Paraná SA. (MINEROPAR).

Carta Geológica de Ponta Grossa/2006 (Folha SG 22- X-C). Disponível em: <www.mineropar.pr.gov.br>. Acesso em: 14 mar. 2010.

Minerais do Paraná SA. (MINEROPAR). Carta Geomorfológica de Ponta Grossa/2006 (Folha SG 22- X-C). Disponível em: <www.mineropar.pr.gov.br>. Acesso em: 14 mar. 2010.

PARANÁ. Companhia Paranaense de Energia (COPEL) 2009 - Índices pluviométricos. Disponível em:< www.suderhsa.pr.gov.br>. Acesso em: 14 abr. 2010.

RAPOSO, A.A.; BARROS, L.F.P; MAGALHÃES JÚNIOR, A.P. O parâmetro de turbidez das águas como indicador de impactos humanos na dinâmica fluvial da bacia do Rio Maracujá - Quadrilátero. In: XIII Simpósio Brasileiro de Geografia Física Aplicada. 13, 2009, Viçosa. Trabalho completo. Disponível em: < http://www.geo.ufv.br/simposio >. Acesso em 07 fev.2011.

SÃO MATEUS DO SUL: História. Disponível em: < https://www.saomateusdosul.pr.gov.br>. Acesso em: 17 jan. 2011.

SÃO PAULO. Secretaria de Meio Ambiente. Companhia Ambiental (CETESB). Índice de Qualidade das Águas. Disponível em: <http://www.cetesb.sp.gov.br>. Acesso em: 08 jun. 2010.

Serviço Social Autônomo PARANACIDADE. Municípios do Paraná. Disponível em: <http://www.paranacidade.org.br/municipios>. Acesso em: 02 nov. 2010. 